\title{
O Labirinto Bergson-Merleau-Pontiano
}

\author{
Luiz Damon Santos Moutinho ${ }^{1}$
}

Para Adriana e Débora

Resumo: $\mathrm{O}$ artigo investiga a presença de Bergson na obra de Merleau-Ponty e o labirinto de questóes que aí se desdobra. Procura mostrar como, na avaliação de Merleau-Ponty, o conceito de natureza em Bergson o impede de passar à história. Para tanto, toma como referência e debate Presença e campo transcendental, de Bento Prado Júnior.

Palavras-Chave: Merleau-Ponty. Bergson. Bento Prado Júnior. Natureza. História. Ontologia.

\section{I}

Merleau-Ponty foi um leitor constante de Bergson. É praxe, entre os comentadores, apontar certa reabilitação de Bergson, na "fase ontológica" de Merleau-Ponty, no momento em que entram em cena os cursos dos anos 1950 sobre "a natureza". Em contrapartida, no primeiro momento, na assim reputada "fase fenomenológica", Bergson apareceria como um alvo, devido ao seu desconhecimento da "intencionalidade". Essa mudança explicitaria o movimento da própria autocrítica de Merleau-Ponty, consubstanciada na passagem da "fenomenologia" à "ontologia". Será esse, por exemplo, o modelo da leitura de Renaud Barbaras.

Barbaras, é certo, tem uma leitura muito sofisticada desse embate bergson-merleau-pontiano: ele aproxima a crítica bergsoniana do nada e a nova redução posta em obra por Merleau-Ponty, nos anos 50. Estaria ali o núcleo da passagem à "ontologia". Voltaremos a isso, em um próximo texto. De nossa parte, não contestamos essa autocrítica; ela é bastante clara, em numerosas passagens da obra de Merleau-Ponty. Pretendemos apenas destacar uma dimensão continuamente obscurecida por essa passagem da "fenomenologia"

\footnotetext{
${ }^{1}$ Professor do Departamento de Filosofia da UFSCar. Autor de Psicologia e fenomenologia em Sartre. São Paulo: Brasiliense, 1995; Razão e experiência. Ensaio sobre Merleau-Ponty. São Paulo: EDUNESP, 2006. E-mail: luizdamon@yahoo.com.br
}

http://dx.doi.org/10.1590/S0101-31732017000200007 
à "ontologia": a dimensão da percepção. Desse modo, para nós, seria mais correto dizer que, entre um momento e outro, há passagem de um modelo a outro da percepção. A leitura de Bergson, por sua vez, deve ser tomada a partir do privilégio da percepção, questão mais ampla que, desde sempre, aproxima Merleau-Ponty de Bergson e o leva a interrogá-lo, e de que Matéria e memória, melhor que o Ensaio, é testemunha-chave. A partir dessa questão, pode-se entâo desdobrar todo o alcance da crítica merleau-pontiana, o que a mera crítica ao desconhecimento da intencionalidade deixa encoberto.

\section{II}

É verdade que, na Fenomenologia da percepção, Merleau-Ponty destaca o modelo do Ensaio, o qual ele interpreta como conduzindo a um "[...] mundo interior tenebroso." (MERLEAU-PONTY, 1995b, p. 71). Ali, no momento de abrir o "campo fenomenal" - saldo provisório da reflexão -, ele opóe a esse campo a "interioridade bergsoniana”, alcançada em uma "coincidência inefável", em que sujeito e objeto "se confundem" (MERLEAUPONTY, 1995b, p. 70). O alvo é destacar o modelo de reflexão, que rejeita precisamente toda possibilidade de "coincidência", seja aquela de uma filosofia transcendental, que reduz o refletido a um correlato da reflexão e, nessa medida, supóe apreendê-lo integralmente, seja aquela de Bergson, que, inversamente, supóe que o sujeito se dilate até o ponto de confundir-se com o objeto: se na filosofia transcendental, o ser é absorvido pelo saber, em Bergson, é o saber que se alarga até fundir-se ao ser (MERLEAU-PONTY, 1995b, p. 76). De um lado, o primado do sujeito; de outro, o do ser. Ora, essa crítica supóe um campo em que nenhum dos termos se deixe absorver pelo outro, e será isso o percebido. Vem daí um estilo de crítica que, nessa primeira fase, se guia por uma dupla negação: a do realismo do em si e a do intelectualismo do para nós. Assim, comentando o primeiro capítulo de Matéria e memória, Merleau-Ponty reconhece que, se, por um lado, Bergson póe que não há em si que não seja para mim, que, portanto, todo esse é já um percipi, por outro lado, lamenta que Bergson não siga essa via até o fim: Bergson afirma um realismo fundado na pré-existência do ser total. O percipi se deduz do esse por degradação e decupagem. O que Merleau-Ponty cobra aqui de Bergson? Meios para explicitar isso mesmo que é o maior ganho de Matéria e memória: Bergson estava a um passo de admitir o primado da percepçáo e, com ele, um tipo de existência intermediária entre o em si e o para si. Mas, para isso, ele não pode simplesmente "se colocar diretamente no ser", para, depois, fazer o recorte 
perceptivo. Ele teria que colocar a questão do sujeito, a "situação do sujeito no ser". Cegueira de Bergson, portanto, para a intencionalidade (MERLEAUPONTY, 2002, p. 84-85). Esse é o meio que permitiria a Bergson escapar às numerosas oscilaçóes que Merleau-Ponty aponta nele.

Que se veja aqui a célebre passagem, ainda do capítulo 1, reiteradamente retomada por Merleau-Ponty: "A verdade é que o ponto $P$, os raios que ele emite, a retina e os elementos nervosos interessados formam um todo solidário, que o ponto luminoso $\mathrm{P}$ faz parte desse todo, e que é em $\mathrm{P}$, e não alhures, que a imagem de P é formada e percebida" (BERGSON, 1959, p. 41 apud MERLEAU-PONTY, 2002, p. 86; MERLEAU-PONTY, 1990, p. 215). O que há de novidade aqui não é a ligação, pois Kant, sustenta MerleauPonty, já mostrara tal ligação. Todavia, o modelo kantiano é o transcendental, essa relação é a de uma "potência ponente a um objeto posto", quer dizer, é o modelo da correlação, o que implica idealizar o objeto e tomá-lo como significação. Em Bergson, cujo modelo é perceptivo, consciência e coisa são ligadas, na medida em que são "absolutamente simultâneas, sem nenhuma prioridade.” (MERLEAU-PONTY, 2002, p. 86; MERLEAU-PONTY, 1990, p. 215). Ora, se aqui Bergson parece entrever um ultrapassamento simultâneo do realismo e do idealismo, aquela existência intermediária entre o em si e o para si, esse ultrapassamento é logo abortado, porque, novamente, seria preciso dar conta da situação do sujeito. Não se demanda aqui uma consciência ativa - o que singulariza a intencionalidade merleau-pontiana - mas um corpo: só o corpo pode "[...] referir-me às coisas pré-existentes" (MERLEAU-PONTY, 2002, p. 86), pois sua visada náo é de "imanência”, como a da consciência e seu objeto, isto é, ele não reduz o objeto a uma significação, porém, é uma visada de "transcendência" e, por isso, a coisa é presente à distância (MERLEAUPONTY, 2002, p. 87).

Mas bem que Bergson tenta restaurar o corpo. Isso demandaria dele pensar a "modalidade existencial" do corpo. Ele não o faz e, por isso, só pode tomar o percipi como degradação do esse (MERLEAU-PONTY, 2002, p. 85). Dá-se o mesmo quanto à síntese do tempo, a síntese do presente e do passado. Se, de um lado, na teoria da percepção pura, o ser é ser percebido, e, se, de outro, na teoria da memória pura, o passado é concebido pelo presente, então, diz Merleau-Ponty, Bergson se dá os elementos para uma "verdadeira dialética do tempo". Se o corpo é o presente, e toda consciência do passado tem uma relação com o corpo - o que justamente permite a Bergson escapar do idealismo kantiano, o qual toma o passado como constituído pela consciência e, por isso 
mesmo, faz o passado perder sua qualidade de passado -, se, pois, ele se dá os instrumentos para pensar o passado a partir do presente, já que ele dota o corpo de uma função na constituição do tempo, ele, no entanto, se suprime os meios de levar adiante essa "dialética do tempo" que aí se abriria, e se suprime em virtude dos "postulados realistas" que assume (MERLEAU-PONTY, 2002, p. 89). O que Merleau-Ponty chama aqui de "postulados realistas" se explicita por essa oscilação que ele explora: se o corpo tem uma "função central", seria preciso mostrar que o mundo é para o corpo (MERLEAU-PONTY, 2002, p. 91), o que, precisamente, Bergson náo faz, de sorte que o corpo aparece como o lugar de passagem de movimentos (MERLEAU-PONTY, 2002, p. 88). Ou, ainda: esse mesmo corpo que tem função na constituição do tempo, pelo que Bergson pode reconhecer uma "memória do corpo" (MERLEAU-PONTY, 2002, p. 89), não será, de outro lado, senão meio para a "memória pura” se realizar (MERLEAU-PONTY, 2002, p. 92), e a memória então escapa ao corpo. A oscilaçáo de Bergson se traduz então em que "[...] ora [ele] nos liga ao presente, e o passado não é mais que virtualidade pura; ora ele nos separa do presente, e é para separar-nos inteiramente do mundo"; não há, assim, "[...] nenhuma passagem do presente ao passado: ou bem lidamos com um passado longínquo, fantasmático, ou bem com um presente sem horizonte temporal.” (MERLEAU-PONTY, 2002, p. 95). Tudo aqui gira em torno aos dois primeiros capítulos de Matéria e memória e a exigência que lhe é feita de seguir a via perceptiva até o fim.

\section{III}

Mas, para além dessas dicotomias que traduzem no fundo a ausência da intencionalidade, há outra questáo levantada por Merleau-Ponty que possibilita desdobrar todo o alcance do modelo perceptivo. Trata-se da questão da ação. Se, em Matéria e memória, por um lado, o corpo se subtrai a respostas automáticas a forças físicas, e essas forças se amortecem em um "centro de indeterminação", isto é, em um ser capaz de ação própria, é verdade, por outro lado, que Bergson pensa a ação como açáo vital. E é aqui que se abre, na versão crítica de Merleau-Ponty, uma nova dicotomia. A açáo vital é aquela pela qual o organismo se mantém na existência (MERLEAU-PONTY, 1990, p. 176, grifo nosso). Merleau-Ponty opóe a tal ação o trabalho, definido precisamente como o "[...] conjunto das atividades pelas quais o homem transforma a natureza física e viva” (MERLEAU-PONTY, 1990, p. 176, grifo nosso): Merleau-Ponty opóe o trabalho como criação ao instinto como preservação. Assim, na versão 
bergsoniana, o trabalho humano, a fabricação de instrumentos são apenas maneiras de "[...] atingir os fins que, por sua vez, o instinto persegue": tratase, em ambos os casos, ação vital e instinto, de "[...] duas soluções divergentes, igualmente elegantes, de um único e mesmo problema” (BERGSON, 1996, p. 144 apud MERLEAU-PONTY, 1990, p. 176, em citação ligeiramente cortada e sem indicação de página). Merleau-Ponty vai explorar essa solução, opondo a ela a especificidade da "ordem humana". Em Bergson, a ação da fala, o trabalho, a vestimenta são compreensíveis apenas "[...] por referência às intençôes da vida": são "[...] meios de adaptação ao 'sólido inorganizado"” (MERLEAU-PONTY, 1990, p. 176): a roupa será uma pelagem artificial, o instrumento substitui o órgão etc. Ora, com isso, salienta Merleau-Ponty, "a ação e a percepção humanas" são ignoradas enquanto tais, isto é, não tem "significação própria" - são reduzidas ao plano "vital”, redução que implica separação entre meios e fim. É preciso tomar a ação não em "referência às intençôes da vida”, contudo, em seu próprio nível, enquanto referida a um objeto. Tomada como adaptação, a questão que então se põe à ação vital é apenas a de saber como se constituem tais objetos da natureza, sem que se pergunte "[...] se é mesmo a objetos desse gênero que a ação e a percepção humanas de início se dirigem.” (MERLEAU-PONTY, 1990, p. 178). É preciso "alargar" a ideia de ação, o que significa não reduzi-la a busca de "fins animais” (MERLEAU-PONTY, 1990, p. 187-8).

Ora, mesma oscilação se verifica aqui, entre um corpo capaz de ação própria e a ação submetida a fins externos. E mesmo critério alimenta a crítica, qual seja, a intencionalidade, definida classicamente por essa referência a X. Só que, desta feita, a crítica explicita o corte que parece alimentá-la: o corte inevitável entre "fins animais" e "fins humanos", ou entre animal e homem. E, de fato, ao distinguir as três ordens - física, vital e humana -, Merleau-Ponty não deixa de notar a originalidade de cada uma delas, por relação à precedente; se a "significação vital" está além das propriedades materiais da ordem física, é verdade também que o "meio animal” em que essa significação aparece é um “[...] meio estável que corresponde aos a priori monótonos da necessidade e do instinto" (MERLEAU-PONTY, 1990, p. 175): a atividade animal encontra seus limites, incapaz, por exemplo, de construir instrumentos que serviriam apenas para construir outros instrumentos, o que, por sua vez, é atestado pelo trabalho humano; isso revela um aspecto da dialética humana: “[...] a capacidade de se orientar em relação ao possível, ao mediato, e não por relação a um meio limitado - o que chamaríamos com Goldstein a atitude categorial." (MERLEAU-PONTY, 1990, p. 190). Daí porque o "meio próprio do homem" 
vai implicar que "[...] vida não tem o mesmo sentido na animalidade e na humanidade" (MERLEAU-PONTY, 1990, p. 188). ${ }^{2}$ A distinção teria, pois, esse traço dominante, apontado pelos críticos de Merleau-Ponty: uma "cisão", um "fosso" entre "natureza" e "cultura", atestado por uma "[...] concepção muito tradicional e limitada da vida como adaptação." (BARBARAS, 2013, p. 15). O preço pago pela exigência da intencionalidade seria então o de retomar uma dualidade entre natureza e história, natureza e cultura, animal e homem. De um lado, uma concepção restritiva da vida, marcada pela repetiçáo; de outro, uma ordem humana em que só ela é suscetível de história. MerleauPonty recairia em um dualismo típico das filosofias da consciência - esse é o teor geral da crítica feita ao "primeiro" Merleau-Ponty.

\section{IV}

Mas isso não é tudo, pois, se se supõe que em Bergson o vital subsuma o humano - e a objeção a isso pode dar em um humano desconectado do vital -, acontece que aquela subsunção não é a verdade de Bergson: ele traça a gênese do instinto e da inteligência, a partir de um impulso vital ainda náo diferenciado, o que não é o mesmo que reduzir a inteligência ao instinto. $\mathrm{E}$, de fato, em debate com a leitura dialetizante de Hyppolite, o qual termina por introduzir negatividade no impulso vital, Bento Prado Júnior lembra que o impulso se póe em ambas as direçóes, como duas tendências, remontando a uma comunidade de origem, de maneira que a divergência se afirma apenas como uma diferenciação (PRADO JÚNIOR, 1989, p. 196-198).

E que seria esse impulso vital? No quarto capítulo de Presença e campo transcendental, quando anuncia a passagem de Evolução criadora a Duas fontes, e na conclusão, quando retoma essa passagem, e de modo sempre abreviado, Bento promove uma "inversão de perspectiva" que responde a essa questão. No quarto capítulo, anuncia a "problemática teológica esboçada em Evolução criadora"; na conclusão, a "inversão" vai mostrar que a "experiência mística", "verdade final de todo o processo evolutivo" (PRADO JÚNIOR, 1989, p. 209), assim como o "impulso vital", não são em verdade senão "ideias-limites que regulam a reflexão", sem dar a esta "fundamento absoluto" (PRADO JÚNIOR, 1989, p. 212). O impulso vital é "apenas uma imagem”, não

\footnotetext{
2 "Sem dúvida, o vestuário, a casa servem para nos proteger do frio. [...] Mas o ato de se vestir torna-se o ato de se embelezar ou o ato do pudor, e revela assim uma nova atitude em face de si mesmo e de outrem. Só os homens veem que estão nus." (MERLEAU-PONTY, 1990, p. 188).
} 
uma "visão em Deus", e por isso ela apenas regula o saber, não lhe oferece fundamento (PRADO JÚNIOR, 1989, p. 212). No entanto, não nos precipitemos. Acompanhemos com Prado Júnior o contraponto entre Sartre e Bergson, sugerido por Merleau-Ponty e tão ricamente desenvolvido por ele. A introdução de Sartre no labirinto bergson-merleau-pontiano vai nos permitir deslindar com mais precisão os múltiplos fios que o tecem.

A “desmistificação da miragem da Ausência”, como diz Prado Júnior, leva Bergson a excluir do Ser toda negatividade; o avesso disso - e essa ênfase devemos a ele (PINTO, 2007) - é secretar toda a negatividade no sujeito: “[...] a subjetividade é pura negatividade." O mundo humano, para Bergson, esse que Merleau-Ponty se propóe descrever a partir da percepção, é - como o é para Sartre - "[...] um chatoiement de néant na superfície do Ser" (PRADO JÚNIOR, 1989, p. 216). A arte de Prado Júnior consistiu em levar a esse inesperado encontro pensamentos radicalmente oponentes: o "positivismo absoluto" de Bergson torna-se um "absoluto negativismo", como, em sentido inverso, o "negativismo absoluto" de Sartre, centrado apenas nas aventuras do para-si ou do nada, se torna um "positivismo absoluto", uma afirmação de um em si massivo. Ora, se dessa aproximação Merleau-Ponty explora uma ontologia renovada, que ultrapasse o exclusivismo entre ser e nada, Prado Júnior, por sua vez, vê aí um mesmo vínculo entre finito e "infinidade" - ou entre a "filosofia da consciência finita" e a "projeção do ideal de sua infinidade" (PRADO JÚNIOR, 1989, p. 217), atestada em Sartre pela ideia, exposta ao termo de $O$ ser e $o$ nada, de que é como se a desintegração entre para si e em si assim se apresentassem "[...] em relação a uma síntese ideal” (PRADO JÚNIOR, 1989, p. 217), e, em Bergson, pela ideia de que a limitação do impulso o conduziria a uma passividade, ou "reatividade", para retomar a tópica nietzschiana, e deixaria a duração de ser "contínua criação de novidade": a essência do impulso consistiria, por conseguinte, não em ser limitado, mas em uma "superação de sua própria finidade", em transposição de seus limites (PRADO JÚNIOR, 1989, p. 200-201). Isso significa que o finito possibilite "[...] sua própria supressão e a instauração de uma nova forma de consciência, o Intellectus Archetypus, a inteligência 'dilatada', tornada co-extensiva à vida." (PRADO JÚNIOR, 1989, p. 201). Acontece, lembra o autor, na última "inversão", que desse impulso temos apenas uma "imagem" - e precisamente porque é "imagem", ele não é mais que um "ideal de infinidade", ideal ao qual remete a consciência finita - tal como ocorre com a "síntese ideal" de Sartre. 
Ora, Prado Júnior não ignora todas as dificuldades e desequilíbrios dessa analogia, e ele mesmo os aponta, quando distingue um autor do outro (PRADO JÚNIOR, 1989, p. 160, 187). No entanto, menos que reiterar tais desequilíbrios, importa relevar ainda um outro aspecto dessa teoria que nos leva a tal ideal, essa que, traçando a gênese da inteligência, chega à criação continuada: tal teoria é "leitura e interpretação" (PRADO JÚNIOR, 1989, p. 193), "passagem da letra ao espírito, do signo ao significado" (PRADO JÚNIOR, 1989, p. 194) - numa palavra, "genealogia" (PRADO JÚNIOR, 1989, p. 195). É assim, conclui o autor, que o ato originário da vida, esse cujo "objeto" não é objeto "já feito", esse que tampouco é para alguém, mas é, ele próprio, o "sujeito" dessa experiência (PRADO JÚNIOR, 1989, p. 181), que, enquanto tal, enquanto "tendência", assegura sua "coesão interna" vencendo resistências que, do exterior, tendem a fixá-lo (PRADO JÚNIOR, 1989 , p. 182), esse ato é uma pura afirmação da vida. Assim, esse ato não é negação da matéria; se fosse, seria apenas "reação", "reatividade". Daí porque, correlativamente, a "adaptação" não seja acomodação, passividade - fenômeno que Merleau-Ponty, por sua vez, julga essencial a sua ontologia. Dá-se o inverso: "[...] não é a vida que se faz contra a matéria; é a matéria que aparece, ao termo do impulso vital, como obstáculo criado pela própria finalidade do impulso [...] Na adaptação, a vida não sofre passivamente a matéria: é a sua afirmação que faz aparecer a matéria como obstáculo." (PRADO JÚNIOR, 1989, p. 184). A afirmação é o dado primário (PRADO JÚNIOR, 1989, p. 185). Daí um Bergson mais próximo de Nietzsche do que de Hegel, conclui Prado Júnior, em um acerto de contas com a leitura dialetizante de Hyppolite. Assim, negatividade e desejo (também obsedado pela "miragem da ausência", pois desqualifica o presente, em nome do ausente) passam para o lado da matéria e da subjetividade. Segue-se daí que a "afirmação da vida" deve conduzir a um "[...] afastamento da experiência antropologicamente determinada, mediada e relativa, na direção de uma experiência imediata, absoluta" (CAPPELLO, 2009, p. 419), ou, nos termos do Prado Júnior, "[...] uma verdadeira superação da condição humana em direção do Absoluto." (PRADO JÚNIOR, 1989, p. 168). Assim, no contraponto a Sartre, cuja reflexão gira em torno ao eixo da negatividade e interdita a filosofia de ir além, Bergson faz movimento inverso, o começo da filosofia estando justamente na passagem à pura positividade e, portanto, na "superação da condição humana" (PRADO JÚNIOR, 1989, p. 188). O que esse contraponto pode então revelar? Que interesse ele tem para Merleau-Ponty? Pode-se daí concluir que a questão se joga em termos de disputa entre humanismo e anti-humanismo? 


\section{V}

Seria um equívoco reduzir a questão a essa querela, e é justamente essa impossibilidade o maior ganho do contraponto, tal como Merleau-Ponty o explora. Ela seria tão encobridora quanto o é a opção do Prado Júnior em explorar, a partir de Merleau-Ponty, uma mesma perspectiva do finito, projetado, em ambos os casos, em um "ideal de infinidade", embora com sentido crítico. A opção de Merleau-Ponty, ao confrontar as duas ontologias, as quais, cada uma a sua maneira, depuram ser e nada, parece ser antes a de mostrar as radicais opçóes excludentes de cada uma: de um lado, Bergson, em sua afirmação da vida, não vê "[...] valor próprio da "inscrição histórica" (MERLEAU-PONTY, 1985, p. 236; grifo do autor), ele "[...] nâo pensou a história de dentro, como havia pensado a vida de dentro" (MERLEAUPONTY, 1985, p. 235); de outro, Sartre, em sua restrição à negatividade, passa em silêncio a natureza e, com isso, ele "se encerra no incorporal", projetando uma "imagem fantástica" do espírito e da história (MERLEAU-PONTY, 1968, p. 91) e que não pode oferecer desta senão uma concepçáo puramente "ética" (MERLEAU-PONTY, 1996, p. 328). Do lado bergsoniano, uma natureza sem história; do lado sartriano, uma história sem natureza; ou, antes, insuficiência da natureza no primeiro e insuficiência da história no segundo, o que os leva, respectivamente, à teologia e ao humanismo.

Para Merleau-Ponty, é uma "questão" saber porque Bergson não se deixa "impregnar" pela história, como se "impregnou" pela vida (MERLEAUPONTY, 1985, p. 237), porque ele náo encontra na história aquilo que encontrou na percepção, quer dizer, aquilo que lhe permitiu "entrelaçar" a nossa duração e a evolução, esta outra duração que "margeia" aquela de fora (MERLEAU-PONTY, 1985, p. 235). Não há, para Bergson, assinala Merleau-Ponty, "vida social", "homens implicados uns nos outros"; há apenas "[...] apelo heróico do indivíduo ao indivíduo, uma mística sem 'corpo místico"” (MERLEAU-PONTY, 1985, p. 237). Ora, essa repulsa da vida social é uma maneira de se "deter", um modo de "eliminar certos possíveis", aqueles mesmos que levariam a história. Assim, quando ele medita sobre ela, ele já a vê projetada a partir do "homem divino" e da "experiência excepcional do místico" (MERLEAU-PONTY, 1985, p. 238). Para retomar a tópica de $A$ estrutura do comportamento: ele não a vê nela mesma. Só que, agora, MerleauPonty acrescenta: ele não a vê como um tecido em que "[...] o bem e o mal persistem juntos" (MERLEAU-PONTY, 1985, p. 237). Surge aqui uma tópica que vai marcar decisivamente a experiência da história: a tópica do mal 
e da violência. Logo aquilo que permanece essencial, para Bergson, o "contato natural com o ser", aparece agora como um contato "sereno" e "tranquilo", marcado pelo "quietismo" (MERLEAU-PONTY, 1985, p. 238; MERLEAUPONTY, 1995a, p. 79) e diante do qual o domínio do mal e as lutas sangrentas da história permanecem sem sentido. O "quietismo" de Bergson "[...] se opõe a toda filosofia da mediação e da história." (MERLEAU-PONTY, 1985, p. 237). E a filosofia vai se apresentar como "[...] o fim da angústia da vertigem" (MERLEAU-PONTY, 1995a, p. 79), a intuição vai implicar "[...] repelir os hábitos da vida ativa" e "[...] fazer desaparecer os problemas" (MERLEAUPONTY, 1995a, p. 79), tornando-os "falsos problemas".

Ora, diante disso, a "afirmação da vida" nada tem da agonística nietzschiana; ao contrário, ela é antes um meio de se preservar da luta e dissolver o problema do mal. Vale notar, de passagem, que a experiência histórica do mal e da violência já era destacada por Sartre como experiência decisiva para sua geração. E, se essa experiência se impóe à reflexão do filósofo, é verdade, contudo, que muito antes de ela acontecer, por ocasião da Segunda Guerra, o projeto filosófico de Sartre já buscava o que ele denominava o "concreto", um campo alargado de experiência que nada queria perder dessa, projeto claramente formulado contra seus predecessores, aí incluído Bergson, então "[...] identificado à causa vaga do espiritualismo", nas palavras de MerleauPonty (MERLEAU-PONTY, 1985, p. 230). É essa antiga tópica que também está em questão para este, ou seja, bem antes da experiência social da guerra, a doutrina já comportava uma passagem à história. E já ali Merleau-Ponty, por sua vez, buscava distinguir-se do caráter antitético da doutrina sartriana pelo modelo da percepção.

\section{VI}

É certo que, nos cursos sobre a natureza, Merleau-Ponty faz nova avaliação de Bergson. No entanto, no que nos interessa aqui, o projeto de vincular natureza e história é preservado. Dessa vez, não mais segundo o modelo que, se, em $A$ estrutura do comportamento, aparece como de integraçáo dialética, depende, contudo, do passo capital da Fenomenologia da percepção, o qual consiste em tomar o tempo como sujeito. Agora, trata-se de introduzir a negatividade no próprio Ser, sem recurso a qualquer tipo de sujeito. No curso de 1956-1957, Merleau-Ponty retoma o tema de seu principal interesse por Bergson: a percepçáo. Bergson "[...] quer voltar à percepção como ato 
fundamental que nos instala nas coisas.” (MERLEAU-PONTY, 1995a, p. 81). Segue-se daí diferença com o idealismo de Berkeley (coisa é representação) e com o realismo (distingue coisa de sua aparição). Assim, a coisa não tem necessidade de ser percebida para ser $e$ há unidade natural entre existência e experiência: “[...] nossa percepção está nas coisas mesmas." É isso agora que quer dizer: "[...] é em $\mathrm{P}$, e não alhures, que a imagem de $\mathrm{P}$ é formada e percebida." Antes, que Merleau-Ponty exigia? A introdução do corpo e sua visada de transcendência, que vai lá nas coisas, até as estrelas, lá nelas mesmas. Agora, trata-se de "[...] pensar a percepção segundo a percepção", como ela se aparece a ela mesma e não segundo a perspectiva realista (MERLEAUPONTY, 1995a, p. 82). Antes, Merleau-Ponty acusava Bergson de incorrer no realismo. Dessa feita, representação e coisa são homogêneas: "[...] a coisa se oferece como anterior a toda percepçáo [...] mas ao mesmo tempo esse universo anterior a mim eu só posso pô-lo tal como o percebo": a coisa é como "[...] um espetáculo que subtende a consciência”. O paradoxo da percepção reside nisso: o Ser é anterior a ela e só é concebível por relação a ela. Bergson tem plena consciência desse paradoxo (MERLEAU-PONTY, 1995a, p. 83). Merleau-Ponty parece agora reconhecer que Bergson ultrapassa o realismo - e o idealismo -, que compreende que ambos vejam "apenas uma metade das coisas", que se trata para ele de "[...] restituir o círculo inteiro, descrever um meio comum ao Ser e à percepção” (MERLEAU-PONTY, 1995a, p. 84). Mas ele tem êxito nisso?

Não. Entretanto, a razão do fracasso não é mais a mesma de antes, isto é, ela não está mais no desconhecimento do corpo e da intencionalidade. Onde está o problema? O foco de Merleau-Ponty vai residir na negatividade implicada pelo paradoxo acima. A "descompressão do Ser total", que advém com minha percepção, é agora a relação entre "[...] o pleno e o vazio, o positivo e o negativo" (MERLEAU-PONTY, 1995a, p. 83). Assim: se “[...] a coisa me aparece [...] como mais real que a percepção”, é necessário, de outro lado, "que haja posição dessa coisa", de onde a "legitimação do oco [creux] a partir do qual se vê a coisa", de sorte que se torna necessário "admitir a prioridade ou simultaneidade do nada que percebe" (MERLEAU-PONTY, 1995a, p. 83-4). Pelo ser percebido "[...] o nada vem ao mundo, e o ser natural perde esta autossuficiência que lhe tinha sido de início concedida." (MERLEAU-PONTY, 1995a, p. 84). De um a outro, há sucessão contínua? Não, pois há "inversão": minha percepção, que era "empobrecimento", é também "positiva": "[...] a coisa tomada nela seria, no fundo, completamente vazia, inarticulada, se não houvesse minha percepção exterior. O nada tem 
um papel positivo.” (MERLEAU-PONTY, 1995a, p. 85). Há aqui uma "superação" e "conservação", uma "[...] contradição" não reconhecida por Bergson, contradição que é a "mola de nossa subjetividade." (MERLEAUPONTY, 1995a, p. 85). Bergson aparece agora "[...] embaraçado diante dessa relação entre Ser e nada.” (MERLEAU-PONTY, 1995a, p. 86). Seu mérito é evidente: busca na experiência do homem o que está no limite dessa experiência. Mas, aparentemente, Matéria e memória não dá conta desse esforço filosófico necessário: por positivismo, faz do "pré-humano" um ser com o qual coexistimos, ao invés de ver nele mistura de ser e de nada (MERLEAUPONTY, 1995a, p. 86).

Passa-se o mesmo quando a natureza é vida. A vida aparece como unidade no ponto de partida, unidade que tende a se desfazer em animais, vegetais, micróbios. Trata-se de um élan comum, de uma natureza viva como impulso (MERLEAU-PONTY, 1995a, p. 88-89). Todavia, essa intuição vai se degenerar, quando a vida aparecer como um princípio indiviso que persegue um fim e é acessível a uma intuição mística (MERLEAU-PONTY, 1995a, p. 89), degeneração que Merleau-Ponty aponta na passagem do capítulo 2 para o capítulo 3 de $A$ evolução criadora. No primeiro caso, haverá necessária discordância entre produtor e produto, "o produtor ultrapassa o produto no próprio ato de cria-lo”, o que é realização mesma da vida. A contingência joga então um papel positivo, o que torna a natureza uma mistura: "[...] a matéria, fazendo obstáculo à vida, lhe dá náo apenas o terreno sobre o qual ela pode se realizar, mas a maneira de se realizar." (MERLEAU-PONTY, 1995a, p. 91). O terreno não é obstáculo para a estrada, ela lhe oferece o indispensável solo. Ora, isso implica que a vida seja não repouso, mas um trabalho de si sobre si (MERLEAU-PONTY, 1995a, p. 91). Essa intuição se degenera, no momento em que a vida se separa de sua operaçáo e se torna um princípio em pensamento (MERLEAU-PONTY, 1995a, p. 91-92): agora, o terreno é um impedimento, pois a estrada buscava apenas a cidade e ela teria querido ser uma linha reta. $\mathrm{O}$ corpo torna-se estorvo: o aparelho de visão é uma redução da potência de ver, causada por necessidade de adaptação: o animal vê apesar dos olhos, e não por seu meio: "[...] do mesmo modo que não é a montanha que faz o túnel, não é o aparelho de visão que faz a visão.” (MERLEAUPONTY, 1995a, p. 92).

Essa passagem, interpretada de modo diferente por Prado Júnior, torna a vida uma realidade transcendente, além de suas "manifestaçôes contingentes" (MERLEAU-PONTY, 1995a, p. 93). Ela se torna uma unidade para além da 
duração, uma "supraconsciência", e é assim que a intuição da Natureza se degenera e cede lugar a Deus (MERLEAU-PONTY, 1995a, p. 93). Prado Júnior, ao contrário, cuida de evitar aqui uma degeneração, introduzindo uma "inversão" pela qual temos apenas uma "imagem" desse Intellectus Archetypus, assegurando assim apenas um vínculo crítico entre o finito e o "ideal de infinidade". Com isso, ele pode manter de pé a tese da "afirmação da vida". Merleau-Ponty, ao contrário, vê aí a afirmação de uma vida que não se faz mais pela matéria, em operação, e assim aparece como "princípio". O alvo de Bergson aparece a Merleau-Ponty como o de eliminar a contingência e questóes como: por que há alguma coisa? (MERLEAU-PONTY, 1995a, p. 94). No entanto, que seria uma força sem sua efetiva operação, que seria uma afirmação sem sua manifestação contingente? Torná-la um "ideal” não resolve a dificuldade.

MOUTINHO, Luiz Damon Santos. The Bergson-Merleau-Ponty labyrinth. Trans/form/ açāo, Marília, v. 40, n. 2, p. 125-138, Abr./Jun., 2017.

ABSTRACT: This paper investigates the presence of Bergson in the work of Merleau-Ponty, and the labyrinth of questions that unfold from there. It shows how, for Merleau-Ponty, Bergson's concept of nature prevented him from moving on to history. For this purpose, we take as a starting point Bento Prado Júnior's "Presença e campo transcendental” (Presence and the transcendental field).

KeYwords: Merleau-Ponty. Bergson. Bento Prado Júnior. Nature. History. Ontology.

\section{REFERÊNCIAS}

BARBARAS, R. Prefácio. In : RAMOS, S. S. A prosa de Dora : uma leitura da articulação entre natureza e cultura na filosofia de Merleau-Ponty. São Paulo: EDUSP, 2013.

BERGSON, H. Matière et mémoire. Paris: PUF, 1959.

L'évolution créatrice. Paris: PUF, 1996.

CAPPELLO, M. A. C. Consciência humana e negação em Bergson. In: GENTIL, H.; CARNEIRO, M. C. Filosofia francesa contemporânea. São Paulo: EDUNESP, 2009. V. 1.

MERLEAU-PONTY. Résumés de cours. Paris: Gallimard, 1968.

. Signes. Paris: Gallimard, 1985.

La structure du comportement. Paris: PUF, 1990.

. La nature. Paris: Seuil, 1995a.

. Phénoménologie de la perception. Paris: Gallimard, 1995b. 
. Le visible et l'invisible. Paris: Gallimard, 1996.

. L'union de l'àme et du corps chez Malebranche, Biran et Bergson. Paris: Vrin, 2002.

PINTO, D. M. Crítica do negativo e ontologia da presença: a interpretação de Bergson segundo Bento Prado Júnior. O Que nos Faz Pensar, v.16, n. 22, p. 23-48, dez. 2007.

PRADO JÚNIOR, B. Presença e campo transcendental: consciência e negatividade na filosofia de Bergson. São Paulo: EDUSP, 1989.

WORMS, F. (Org.). Annales bergsoniennes I: Bergson dans le siècle. Paris: PUF, 2002.

Recebido em 31/01/2017

Aceito em 27/02/2017 